\title{
STRATEGI AKTIF (MOVING AVERAGE) DAN STRATEGI PASIF (BUY-AND-HOLD STRATEGI) PADA PEMBENTUKAN PORTOFOLIO PERIODE 2 JANUARI 2012 - 28 DESEMBER 2012
}

\author{
Loddy Li Putra (Loddy.lie1 $1 @ y a h o o . c o . i d)$ \\ Werner R. Murhadi (wernermurhadi@gmail.com) \\ Putu Anom Mahadwartha (Anom@staff.ubaya.ac.id) \\ Manajemen / Fakultas Bisnis dan Ekonomika, Universitas Surabaya
}

\begin{abstract}
This study aims to test whether active strategies with Moving averages are superior to the passive strategy Buy-and-Hold Strategy in stock portfolios formed based on LQ45 index. Research method used in the research begins with the collection of data which is then processed and analyzed. Subsequently Application ChartNexus used in order to form MA5\&MA20 and MA10\&30. Lastly the research compare return from active strategies (moving average) and the passive strategy (buy-and-hold strategy). The results of this study indicate that passive strategy with buy-and-hold strategy is able to outperform the moving average active strategy when the market is bullish.
\end{abstract}

Keywords: Active and Passive Strategy, Trendline, Portofolio, Return

\section{PENDAHULUAN}

Investasi pada hakikatnya merupakan penempatan sejumlah dana pada saat ini dengan harapan dapat menghasilkan keuntungan di masa depan (Halim, 2005). Investasi menjadi penting karena tidak ada yang dapat memprediksi secara akurat, apa yang akan terjadi pada kondisi keuangan yang dapat berdampak pada kehidupan seseorang. Dengan berinvestasi maka dapat mengurangi risiko yang dapat timbul dari ketidakpastian tersebut. Saham merupakan salah satu jenis instrumen investasi. Saham dapat didefinisikan sebagai tanda penyertaan atau pemilikan seseorang atau badan dalam suatu perusahaan (Widoatmodjo, 2000: 43). Keuntungan yang dapat diperoleh dari saham adalah berupa dividen dan capital gain. Dalam pemilihan saham investor atau trader perlu melakukan analisis terlebih dahulu. Analisis saham dibagi menjadi 2 yaitu, analisis fundamental dan analisis teknikal. Analisis fundamental mencakup informasi mengenai laporan keuangan dan kesehatan perusahaan, manajemen, pesaing, dan situasi pasar dari produk tersebut (Ellen May,2011:34). Sedangkan, Analisis teknikal adalah metode untuk memprediksi pergerakan harga dan trend pasar di masa depan dengan mempelajari grafik dari aksi pasar dimasa lalu dengan mempertimbangkan harga instrumen dan minat atas instrumen tersebut (Cahyono, 2001: 9). Analisis teknikal merupakan tools yang dapat membantu pembuatan keputusan oleh para investor, terlebih lagi oleh seorang trader dalam menentukan posisi buy, hold, dan sell. Berdasarkan hal tersebut, peneliti memfokuskan penelitian pada analisis teknikal modern, khususnya metode Moving Average (MA).

Moving Average (MA) adalah indikator yang paling populer dan paling luas digunakan oleh para trader karena sangat mudah digunakan ataupun dianalisa (Edianto Ong,2008:277). Dalam penelitian ini peneliti menggunakan metode EMA (Exponential Moving Average) sebagai strategi aktif karena metode ini merupakan penyempurnaan dari kekurangankekurangan yang ditumbulkan, dari 2 jenis metode Moving Average (MA) sebelumnya. Objek penelitian ini menggunakan index saham LQ45 yang merupakan gabungan dari 45 saham, yang listing di BEl dengan tingkat likuiditas dan kapitalisasi yang tinggi sehingga dapat meminimalkan risiko karena memilih saham-saham dengan risiko lebih rendah dibanding saham-saham lain. 


\section{Loddy Li Putra \\ Werner R. Murhadi \\ Putu Anom Mahadwartha}

Interpretasi random walk hypothesis menyatakan bahwa perubahan harga masa depan adalah independen dari pergerakan harga masa lampau. Teori ini tentunya bertentangan dengan teknik analisis teknikal yang menjadi penelitian, karena analisis teknikal menyatakan bahwa harga di masa lampau dapat memprediksi harga di masa akan datang dan memberikan keuntungan bagi investor.

Ibnu Khajar (2011) melakukan penelitian dengan menggunakan saham-saham indeks LQ45 periode Agustus 2009 sampai Januari 2010, yang kemudian membentuk portofolio optimal dengan metode single index model. Dari portofolio saham optimal tersebut dilakukan perbandingan return dengan menggunakan strategi aktif dan strategi pasif. Hasil penelitian Ibnu Khajar (2011) menunjukan hasil strategi aktif dengan return yang lebih unggul daripada strategi pasif. Return tersebut diikuti dengan risiko yang tinggi pula, karena sifat kedua linear. Fernando Fernandez-Rodriquez, Christian Gonzalez-Martel, dan Simon Sosvilla-Rivero (2000), menemukan dalam penelitian mereka di pasar modal Madrid bahwa buy-and-hold strategy lebih unggul ketika kondisi pasar bullish.

Penelitian ini bertujuan membandingkan kinerja analisis teknikal (moving average) dalam memberikan return kepada investor atau trader, dibandingkan strategi pasif (buy-and-hold strategy). Hasil penelitian ini nantinya diharapkan dapat menjadi acuan bagi investor atau trader, khususnya bagi mereka yang masih baru dalam dunia pasar modal. Penelitian ini juga dapat menjadi pertimbangan investor dalam memilih strategi investasi yang akan digunakan.

\section{METODE PENELITIAN}

Penelitian ini menggunakan return sebagai variabel yang diteliti. Return adalah total keuntungan atau kerugian terhadap suatu investasi selama periode waktu tertentu (Gitman, 2009 , 228). Penelitian ini menggunakan jenis data sekunder, saham-saham di BEl yang termasuk dalam indeks LQ45. Data grafik pergerakan harga saham akan diperoleh dari software ChartNexus. Harga saham yang digunakan adalah harga penutupan (closing price), ketika terjadi signal beli atau signal jual.

Data akan diperoleh dengan menyeleksi saham yang berada dalam indeks LQ45, berdasarkan kapitalisasi pasar dan trenline pergerakan harga saham. Berikut merupakan prosedur pengumpulan data:

1. Mencari data saham indeks LQ45 selama periode tahun 2012.

2. Melakukan seleksi 45 saham indeks LQ45 menjadi 15 saham, berdasarkan kapitalisasi pasar.

3. Melakukan seleksi kembali terhadap 15 saham tersebut berdasarkan garis trendline.

Dalam melakukan penelitian ini, beberapa langkah-langkah yang dilakukan, sebagai berikut :

1. Melakukan pemilihan 15 saham dalam LQ45 berdasarkan kapitalisasi pasar terbesar.

2. Menentukan periode waktu moving average pendek (short term) 5 hari dan moving average panjang (long-term) 20 hari (Ellen May, 2011, 48). Moving average pendek 10 hari dan moving average panjang 30 hari. (Edianto Ong, 2008, 277).

3. Menghitung return 15 saham yang tergabung dalam portofolio berdasarkan strategi aktif dan strategi pasif.

4. Membuat perbandingan hasil dari strategi aktif dan strategi pasif.

Kapitalisasi merupakan syarat dalam pembentukan portofolio. Portofolio dibentuk dari 15 saham berdasarkan rekomendasi dari penelitian Tendelilin pada pasar modal di Indonesia (Tandelilin, 2010, 113). Langkah-langkah yang dilakukan dalam pembentukan portofolio, sebagai berikut:

1. Memperoleh data kapitalisasi pasar Indeks LQ45 pada awal periode tahun 2012. 
2. Memilih 15 saham dari 45 saham dalam indeks LQ45, dengan urutan kapitalisasi terbesar dan trendline bullish selama 1 tahun.

3. Menyeleksi kembali 15 saham yang terpilih dengan menggunakan garis trendline support dan resisten, pada periode satu tahun sebelum tahun penelitian (tahun 2011). Saham yang menghasilkan kondisi pasar yang sedang naik (bullish), yang masuk dalam portofolio. Jika saham menunjukan kondisi yang menurun (bearish) yang kuat, maka saham tersebut tidak masuk dalam portofolio meskipun saham tersebut berkapitaliasi 15 besar. Jika menunjukan trend yang tidak jelas atau trend turun (downtrend) yang lemah, maka akan digunakan trendline setengah tahun. Saham yang menunjukan downtrend akan digantikan dengan saham kapitalisasi besar lainnya (no 16, dan seterusnya).

\section{HASIL DAN PEMBAHASAN}

Tabel 1

Portofolio Berdasarkan Kapitalisasi Dan Trendline Indeks LQ45

\begin{tabular}{|c|c|l|r|c|}
\hline NO & KODE & \multicolumn{1}{|c|}{ NAMA EMITEN } & $\begin{array}{c}\text { KAPITALISASI PASAR PER } \\
31-J A N-2012\end{array}$ & STATUS \\
\hline 1 & ASII & PT Astra International Tbk & 319.415 .234 .274 .600 & TETAP \\
\hline 2 & BBCA & PT Bank Central Asia Tbk & 195.267 .672 .960 .000 & TETAP \\
\hline 3 & BBRI & PT Bank Rakyat Indonesia Tbk & 167.293 .922 .103 .000 & TETAP \\
\hline 4 & BMRI & PT Bank Mandiri (Persero) Tbk & 154.769 .999 .993 .300 & TETAP \\
\hline 5 & UNVR & PT Unilever Indonesia Tbk & 149.548 .000 .000 .000 & TETAP \\
\hline 6 & TLKM & PT Telekomunikasi Indonesia Tbk & 138.095 .995 .068 .000 & TETAP \\
\hline 7 & GGRM & PT Gudang Garam Tbk & 109.673 .016 .000 .000 & TETAP \\
\hline 8 & UNTR & PT United Tractors Tbk & 105.749 .331 .105 .600 & TETAP \\
\hline 9 & PGAS & PT Perusahaan Gas Negara Tbk & 81.815 .090 .161 .500 & TETAP \\
\hline 10 & SMGR & PT Semen Indonesia (Persero) & 67.026 .176 .000 .000 & TETAP \\
\hline 11 & BBNI & PT Bank Negara Indonesia Tbk & 66.925 .365 .862 .125 & TETAP \\
\hline 12 & INTP & $\begin{array}{l}\text { PT Indocement Tunggal Prakasa } \\
\text { Tbk }\end{array}$ & 62.396 .877 .298 .050 & TETAP \\
\hline 13 & ADRO & PT Adaro Energy Tbk & 58.534 .310 .460 .000 & TETAP \\
\hline 14 & INDF & PT Indofood Sukses Makmur Tbk & 42.146 .047 .200 .000 & BARU \\
\hline 15 & CPIN & $\begin{array}{l}\text { PT Charoen Pokphand Indonesia } \\
\text { Tbk }\end{array}$ & 40.995 .000 .000 .000 & BARU \\
\hline 16 & BUMl & PT Bumi Resources Tbk & 52.972 .170 .000 .000 & KELUAR \\
\hline 17 & PTBA & PT Tambang Batubara Bukit & 46.428 .256 .777 .500 & KELUAR \\
\hline A & & & \\
\hline
\end{tabular}

Sumber : Diolah

Tabel 1 merupakan portofolio yang terbentuk berdasarkan nilai kapitalisasi terbesar yang kemudian diseleksi lagi menggunakan garis trendline. Berikut merupakan garis trendline saham yang keluar dan masuk dari portofolio. 


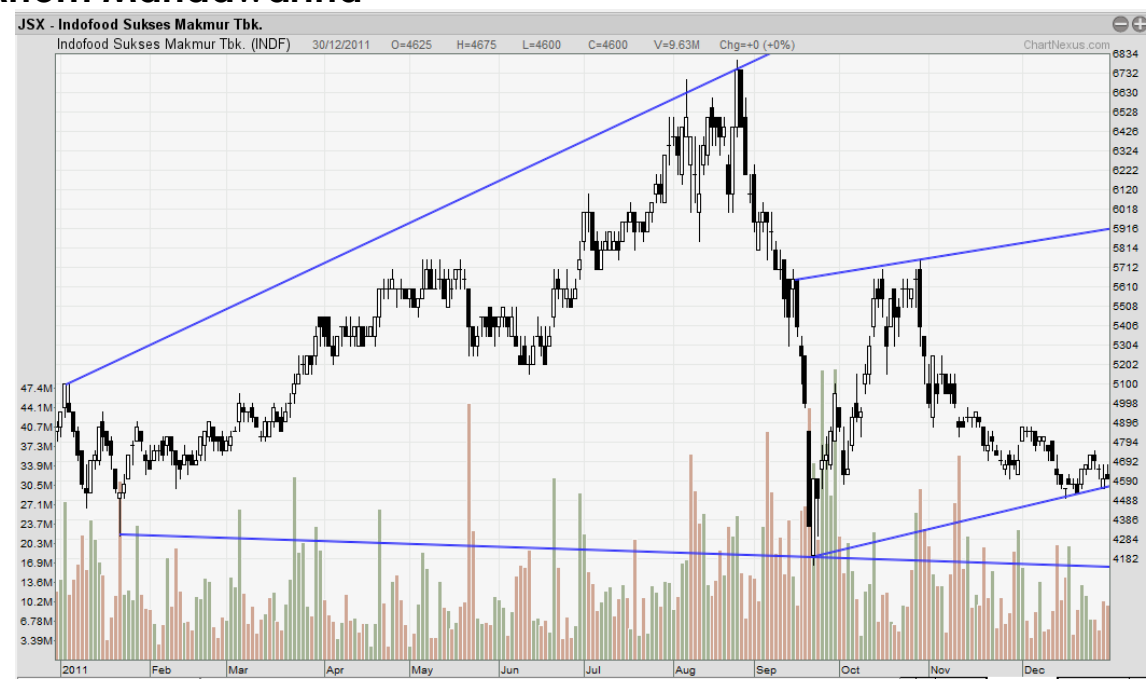

\section{Gambar 1}

Contoh Trendline: INDF 3 Januari 2011 - 30 Desember 2011

Gambar 1 adalah trendline INDF yang merupakan pengganti PTBA yang keluar dari portofolio karena menujunkan trend turun. Pada gambar 1 terdapat 2 garis trendline support dan resisten. Trendline pertama menunjukan trend yang kurang jelas, maka digunakan trendline kedua menunjukan uptrend yang jelas. Saham INDF memenuhi ketentuan untuk masuk dalam portofolio.

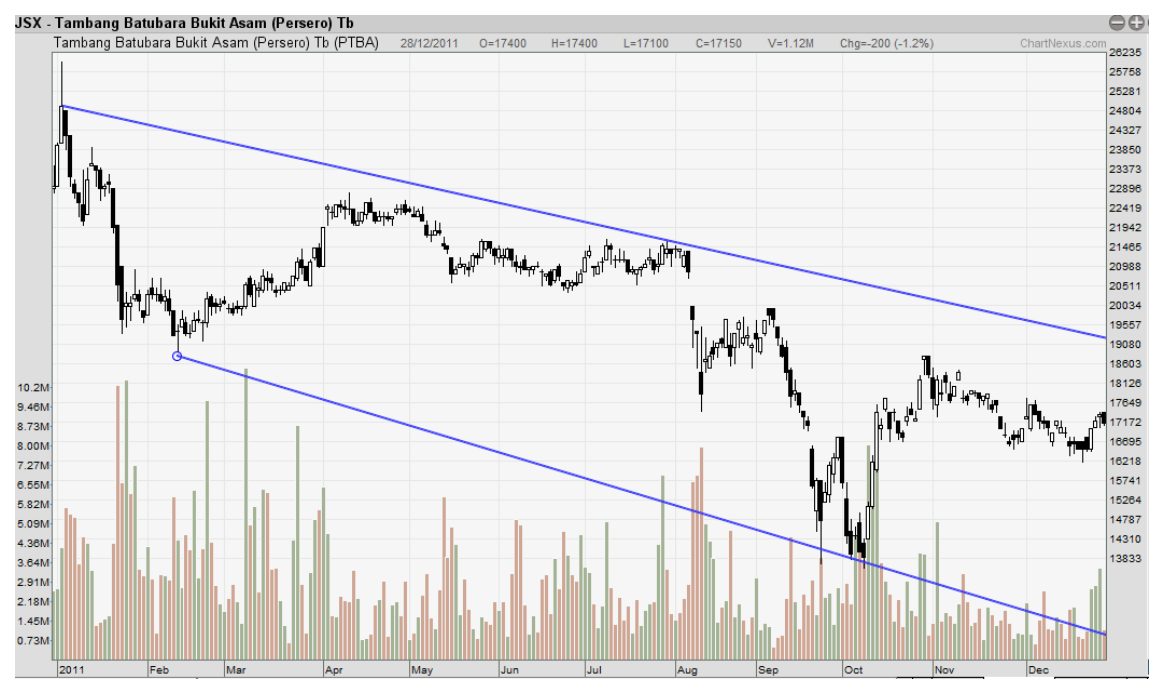

Gambar 2

Contoh Trendline: PTBA 3 Januari 2011 - 30 Desember 2011

Gambar 2 menunjukan garis downtrend yang jelas, maka saham PTBA tidak memenuhi ketentuan untuk masuk dalam portofolio. Saham PTBA akan digantikan oleh saham berkapitalisasi besar ke-17 (INDF).

Setelah portofolio ditetapkan maka dilakukan analisa dengan menggunakan grafik pergerakan harga saham menggunakan aplikasi chartnexus. Diantara lima belas saham dalam portofolio, saham PT Charoen Pokphand Indonesia TbK (CPIN) menghasilkan return paling besar diantar saham lain dalam portofolio. 


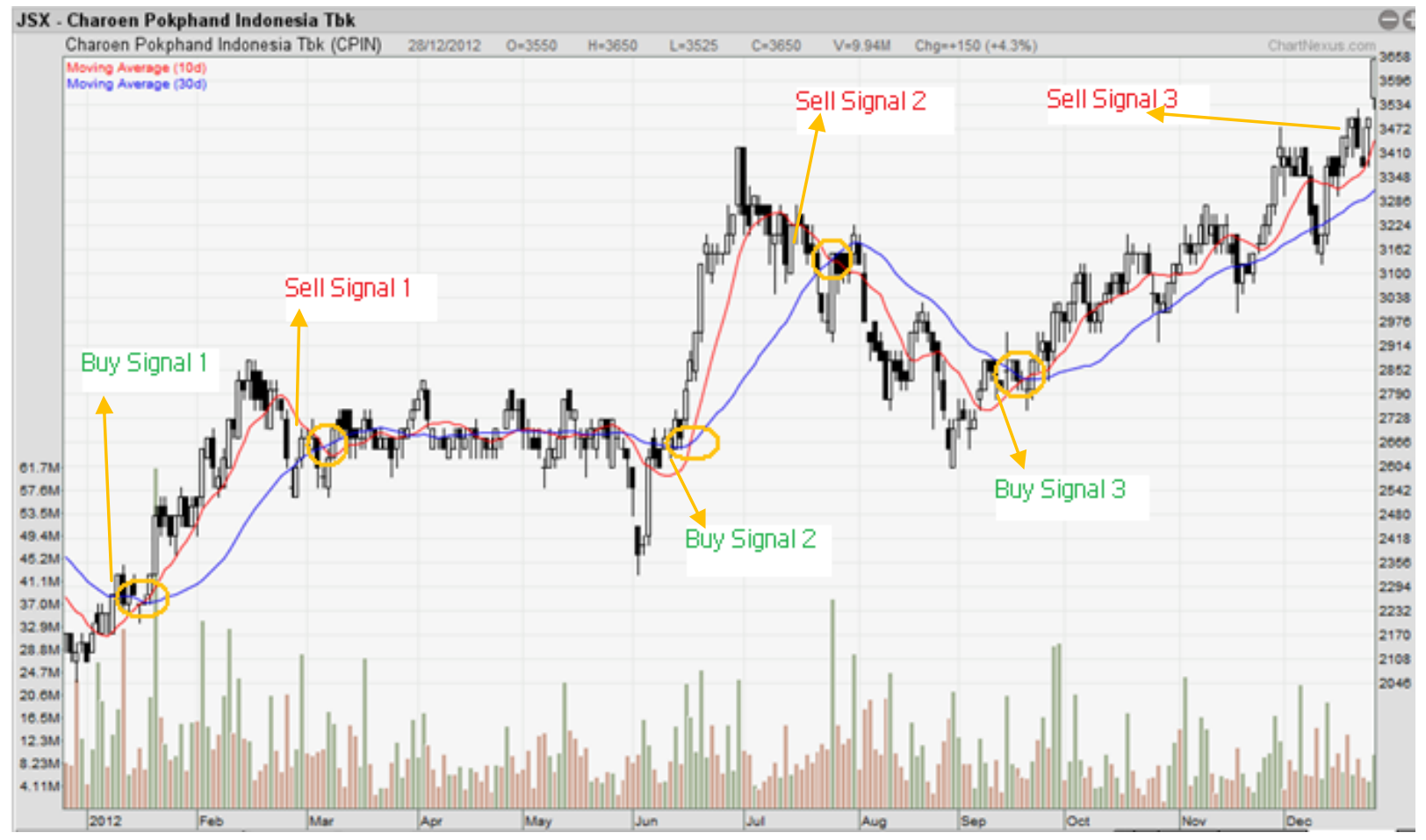

Gambar 3

Moving Average CPIN 2 Januari 2012 - 28 Desember 2012 Short MA 10 hari \& long MA 30 hari

Gambar 3 menunjukan pergerakan harga saham PT. Charoen Pokphand Indonesia Tbk, selama tahun 2012. Berdasarkan pergerakan moving average terdapat 6 signal (buy signal dan sell signal).

Tabel 2

Return Saham CPIN berdasarkan Short MA 10 hari dan long MA 30 hari

\begin{tabular}{|c|c|c|c|c|}
\hline Tanggal Transaksi & Harga & Jumlah Lot & Kapitalisasi & Return \\
\hline 18 januari (buy) & Rp 2.325 & 43 & $\operatorname{Rp} 49.987 .500$ & \\
\hline 7 Maret (sell) & Rp 2.625 & 43 & Rp 56.437 .500 & $12,9 \%$ \\
\hline 19 Juni (buy) & Rp 2.950 & 38 & Rp 56.050 .000 & \\
\hline 26 Juli (sell) & $\mathrm{Rp} \quad 3.100$ & 38 & Rp 58.900 .000 & $5,08 \%$ \\
\hline $\begin{array}{ll}21 & \text { September } \\
\text { (buy) } & \\
\end{array}$ & Rp 2.875 & 41 & Rp 58.937.500 & \\
\hline 28 Desember (sell) & Rp 3.650 & 41 & $\mathrm{Rp} 74.825 .000$ & $27,0 \%$ \\
\hline \multicolumn{4}{|c|}{ Total Return } & $44,94 \%$ \\
\hline
\end{tabular}

Berdasarkan moving average pendek 10 hari dan moving average panjang 30 hari, diperoleh persentase total return CPIN selama periode 2012 adalah sebesar $44,94 \%$. 
Return Saham Berdasarkan Strategi pasif (Buy-and-Hold Strategy) Buy 2 Januari 2012 dan Sell 28 Desember 2012

\begin{tabular}{|l|l|lc|c|cc|c|}
\hline Saham & Transaksi & \multicolumn{2}{|c|}{ Harga } & Lot & \multicolumn{2}{c|}{ Kapitalisasi } & Return \\
\hline \multirow{2}{*}{ CPIN } & Buy & $\mathrm{Rp}$ & 2.100 & 47 & $\mathrm{Rp}$ & 49.350 .000 & \\
& Sell & $\mathrm{Rp}$ & 3.650 & 47 & $\mathrm{Rp}$ & 85.775 .000 & $73,81 \%$ \\
\hline
\end{tabular}

Tabel 3 menunjukan return saham CPIN dengan menggunakan strategi pasif (buy-and-hold strategy) yang menghasilkan return $73,81 \%$ dan mampu mengungguli return saham yang dihasilkan dengan strategi aktif (moving average) yang hanya menghasilkan return sebesar $44,94 \%$.

Tabel 4

Perbandingan return strategi aktif dan strategi pasif

\begin{tabular}{|l|r|r|r|}
\hline STOCK & MA 10 \& MA 30 & MA 5 \& MA 20 & Buy\&Hold Strategy \\
\hline ASII & $10,31 \%$ & $7,26 \%$ & $3,12 \%$ \\
\hline BBCA & $17,11 \%$ & $20,41 \%$ & $13,75 \%$ \\
\hline BBRI & $14,91 \%$ & $8,55 \%$ & $2,21 \%$ \\
\hline BMRI & $12,22 \%$ & $12,36 \%$ & $20,90 \%$ \\
\hline UNVR & $12,72 \%$ & $9,01 \%$ & $12,40 \%$ \\
\hline TLKM & $19,05 \%$ & $25,95 \%$ & $28,37 \%$ \\
\hline GGRM & $-19,04 \%$ & $-13,35 \%$ & $-9,63 \%$ \\
\hline UNTR & $-17,73 \%$ & $0,58 \%$ & $-24,23 \%$ \\
\hline PGAS & $14,74 \%$ & $34,80 \%$ & $49,59 \%$ \\
\hline SMGR & $34,64 \%$ & $25,91 \%$ & $41,52 \%$ \\
\hline BBNI & $-1,89 \%$ & $4,91 \%$ & $-3,27 \%$ \\
\hline INTP & $13,19 \%$ & $16,94 \%$ & $30,90 \%$ \\
\hline ADRO & $-27,31 \%$ & $3,07 \%$ & $-9,66 \%$ \\
\hline INDF & $14,54 \%$ & $13,41 \%$ & $26,49 \%$ \\
\hline CPIN & $44,94 \%$ & $41,42 \%$ & $73,81 \%$ \\
\hline
\end{tabular}

Tabel 4 merupakan total return dari masing-masing saham untuk setiap strategi. Strategi pasif (buy-and-hold strategy) menghasilkan total return tertinggi $(256,26 \%)$ dan strategi aktif (MA10 \& MA30) menghasilkan total return terendah (142,39\%). Rata-rata saham dengn return tertinggi dihasilkan buy-and-hold strategy, sedangkan rata-rata MA10 \& MA30 menghasilkan return terendah paling banyak.

\section{KESIMPULAN}

Berdasarkan hasil penelitian rata-rata strategi pasif (buy-and-hold strategy) menghasilkan return yang lebih unggul dibandingkan strategi aktif (moving average). Hal tersebut didukung oleh kondisi pasar modal Indonesia yang sedang bullish. Dapat disimpulkan bahwa penggunaan strategi pasif (buy-and-hold strategy) dapat memberikan hasil yang lebih unggul, bila digunakan pada kondisi pasar yang sedang bullish. Sedangkan, pada kondisi bearish strategi pasif akan memberikan kerugian yang lebih besar dibanding strategi aktif (moving average).

Berdasarkan hasil penelitian ini, peneliti dapat memberikan beberapa rekomendasi yang mungkin dapat dijadikan pertimbangan untuk penelitian selanjutnya, antara lain: 
1. Penelitian ini menggunakan portofolio saham-saham berkapitalisasi besar yang mampu memberikan pengaruh pergerakan pada pasar. Portofolio diambil dari indeks LQ45 yang merupakan kumpulan saham-saham bluechip dan teraktif. Penelitian selanjutnya dapat membentuk portofolio berdasarkan salah satu dari indeks sektoral, seperti finance, property, consumer, mining, agriculture, basic industries, misc industries, infrastructure, dan trade\&manufacture.

2. Penelitian ini menggunakan dua periode waktu untuk strategi aktif Moving Average, yaitu short MA5 \& long MA20 dan short MA10 \& long MA30. Maka dari itu, penelitian selanjutnya dapat menggunakan periode waktu yang berbeda. Periode waktu penelitian disesuaikan dengan preference investor. Contoh MA lainnya seperti, MA15, MA60, MA100, MA200.

3. Penelitian ini menggunakan rentang waktu harian (day trading) selama 1 tahun dari 2 Januari 2012 hingga 28 Desember 2012, dan pada kondisi pasar normal yang cenderung bullish. Penelitian selanjutnya dapat menggunakan rentang waktu bulanan atau tahunan dan kondisi pasar yang sedang bearish atau stabil.

4. Penelitian ini melihat dari satu jenis analisis teknikal dari banyak analisis teknikal yang ada. Terdapat beberapa analisis teknikal yang dapat dibandingkan dengan strategi pasif (buy-and-hold strategy). Semua jenis analisis teknikal yang ada tidak dapat menyimpulkan bahwa akan menghasilkan kesimpulan atau hasil yang sama.

5. Penelitian ini tidak memperhitungkan biaya transaksi dalam setiap transaksi jual maupun beli yang dilakukan.

\section{DAFTAR REFERENSI}

Ardani, N., 2012, Investasi: Komparasi Strategi Buy and Hold dengan Pendekatan Teknikal, Jurnal Akuntansi dan Keuangan, Vol 14: 1.

Eko, U., 2008, Analisis dan Penilaian Kinerja Portofolio Optimal Saham-Saham LQ45, Jurnal IImu Administrasi dan Organisasi, Vol 15: 3.

Fernandez-Rodriguez, F., Gonzalez-Martel, C., dan Sosvilla-Rivero, S., 2000, On the profitability of technical trading rules based on artificial neural networks: Evidence from the Madrid stock market, Working Paper, Universidad de Las Palmas de Gran Canaria, Las Palmas, Canary Islands, Spain.

Khajar, I., 2011, Startegi Aktif Pasif dalam Optimalisasi Portofolio Saham Indeks LQ45, Jurnal Keuangan dan Perbankan, Vol 15: 2.

Kilgallen, T., 2012, Testing The Simple Moving Average Across Commodities, Global Stock Indices, and Currencies, Journal of Wealth Management, Vol 15: 1.

May, E., 201 1, Smart Traders Not Gamblers, Gramedia Pustaka Utama.

Murphy, J.J., 1999, Technical Analysis of the Financial Markets: A Comprehensive Guid to Trading Methods and Applications, rev. ed., New York Institute of Finance.

Monica, A., 2010, Analisis Return saham dengan indikator variable Moving Average pada saham-saham sektor pertambangan di Bursa Efek Indonesia periode 2006 - 2007, Skripsi, Universitas Surabaya.

Ong, E., 2011, Technical Analysis for Mega Profit, 7th edition, Gramedia Pustaka Utama Tandelilin, E., 2010, Portofolio dan Investasi, Kanisius.

Wijaya, J., 2010, Analisis return Moving Average Convergence Divergence dan Buy-and-Hold Strategy pada LQ45 periode Februari 2006 - Januari 2009, Skripsi, Universitas Surabaya.

Wiksuana, I.G.B, 2009, Kinerja Portofolio Saham Berdasarkan Strategi Investasi Momentum di Pasar Modal Indonesia, Jurnal Manajemen dan Kewirausahaan, Vol 11: 1.

www.idx.co.id diunduh pada tanggal 20 Maret 2013.

http://en.wikipedia.org/wiki/Moving_average diunduh pada tanggal 14 Maret 2013.

http://www.britama.com/index.php/indeks-saham-bei/indeks-lq45/ diunduh pada tanggal 1 April 2013. 